\title{
Communication
}

\section{Chronic Exposure to Deoxynivalenol Has No Influence on the Oral Bioavailability of Fumonisin $B_{1}$ in Broiler Chickens}

\author{
Gunther Antonissen 1,2,*, Mathias Devreese 1, Filip Van Immerseel ${ }^{2}$, Siegrid De Baere ${ }^{\text {, }}$ \\ Sabine Hessenberger ${ }^{3}$, An Martel $^{2}$ and Siska Croubels ${ }^{1}$
}

1 Department of Pharmacology, Toxicology and Biochemistry, Faculty of Veterinary Medicine, Ghent University, Salisburylaan 133, Merelbeke 9820, Belgium;

E-Mails: Mathias.Devreese@ugent.be (M.D.); Siegrid.DeBaere@ugent.be (S.D.B.);

Siska.Croubels@ugent.be (S.C.)

2 Department of Pathology, Bacteriology and Avian Diseases, Faculty of Veterinary Medicine, Ghent University, Salisburylaan 133, Merelbeke 9820, Belgium;

E-Mails: Filip.VanImmerseel@ugent.be (F.V.I.); An.Martel@ugent.be (A.M.)

3 Biomin Research Center, Technopark 1, Tulln 3430, Austria;

E-Mail: Sabine.Hessenberger@biomin.net

* Author to whom correspondence should be addressed; E-Mail: Gunther.Antonissen@ugent.be; Tel.: +32-9-264-7434; Fax: +32-6-264-7497.

Academic Editor: Sven Dänicke

Received: 9 December 2014 / Accepted: 9 February 2015 / Published: 16 February 2015

\begin{abstract}
Both deoxynivalenol (DON) and fumonisin $\mathrm{B}_{1}\left(\mathrm{FB}_{1}\right)$ are common contaminants of feed. Fumonisins (FBs) in general have a very limited oral bioavailability in healthy animals. Previous studies have demonstrated that chronic exposure to DON impairs the intestinal barrier function and integrity, by affecting the intestinal surface area and function of the tight junctions. This might influence the oral bioavailability of $\mathrm{FB}_{1}$, and possibly lead to altered toxicity of this mycotoxin. A toxicokinetic study was performed with two groups of 6 broiler chickens, which were all administered an oral bolus of $2.5 \mathrm{mg} \mathrm{FBs} / \mathrm{kg}$ BW after three-week exposure to either uncontaminated feed (group 1) or feed contaminated with $3.12 \mathrm{mg}$ DON/kg feed (group 2). No significant differences in toxicokinetic parameters of $\mathrm{FB}_{1}$ could be demonstrated between the groups. Also, no increased or decreased body exposure to $\mathrm{FB}_{1}$ was observed, since the relative oral bioavailability of $\mathrm{FB}_{1}$ after chronic DON exposure was $92.2 \%$.
\end{abstract}


Keywords: Fusarium toxins; deoxynivalenol; fumonisin $\mathrm{B}_{1}$; broiler chickens; toxicokinetics; oral bioavailability

\section{Introduction}

Mycotoxins are a structurally diverse group of secondary metabolites produced by several fungal genera [1]. Molds belonging to the Fusarium genus are commonly affecting feed and food in climatological moderate regions [2]. A worldwide survey on the occurrence and contamination levels of mycotoxins in finished feed for poultry, swine and dairy cows, and feed raw materials indicate that the fusariotoxins deoxynivalenol (DON) and fumonisins (FBs) are the most frequently detected mycotoxins, respectively contaminating $55 \%$ and $54 \%$ of the 17,316 investigated samples [3]. However, taking into consideration that mycotoxigenic fungi are usually capable of producing more than one mycotoxin, and that feed raw materials are commonly infected with various fungal species at a time, it is very common for feed commodities to be contaminated with different mycotoxins. A study of Streit et al. [3], reported that in 53\% of the contaminated samples more than one mycotoxin was detected. The final mycotoxin profile of compound feed is also influenced by the levels of the different feed raw materials [4].

The intestinal tract acts as a dynamic barrier, which regulates the entry of foreign antigens into the underlying tissues including food proteins, xenobiotics (such as drugs and mycotoxins), commensal microbiota and pathogens [5]. Following the oral intake of mycotoxin-contaminated feed, the intestinal epithelium will be exposed to high concentrations of mycotoxins $[5,6]$. Since the main toxic effect of DON at the cellular level is the inhibition of protein synthesis, rapidly proliferating cells in tissues with a high protein turnover, such as the small intestine, are most affected [7]. Several studies demonstrated a negative effect of DON on the intestinal morphology. DON decreases the total intestinal absorption surface area for nutrients by reducing the villus height and crypt depth [8-11]. Furthermore, several in vitro and in vivo studies reported that DON alters the intestinal epithelial integrity and permeability, by affecting the function of the tight junctions $[8,9,12]$. As a result of the negative impact of DON on the intestinal integrity, DON is able to increase the translocation of septicemic E. coli and increase the permeability to doxycycline and paromomycin over porcine intestinal epithelial cell monolayers [12,13].

As stated above, in addition to DON, FBs are ubiquitous contaminants of corn and other grain products. FBs are produced by Fusarium verticillioides, F. proliferatum, and other Fusarium species [14]. More than 28 fumonisin homologues have been described, with fumonisin $\mathrm{B}_{1}\left(\mathrm{FB}_{1}\right)$ as the most thoroughly investigated because of its frequent occurrence and toxicological importance. Fumonisin $\mathrm{B}_{2}$ $\left(\mathrm{FB}_{2}\right), \mathrm{FB}_{3}$ and $\mathrm{FB}_{4}$ are less prevalent, and are structurally different from $\mathrm{FB}_{1}$ in the number and position of hydroxyl groups $[14,15]$. FBs mainly act by inhibiting sphinganine $N$-acyl transferase and consequently disrupt the ceramide and sphingolipid metabolism [16]. Liver, kidneys and the intestinal tract are target organs of FBs toxicity in most animal species [14,17,18]. However, species-specific differences exist in the main affected organs. In horses, $\mathrm{FB}_{1}$ mainly affects the brain inducing leukoencephalomalacia, while in pigs the heart and lungs are the most important target organs of $\mathrm{FB}_{1}$, 
causing pulmonary edema [14]. Poultry are often considered to be quite resistant toward the deleterious effects of FBs, although important differences are observed depending on the age [19] and species [20-24]. Increased mortality due to $\mathrm{FB}_{1}$ has only been demonstrated in broiler chicks during the first three days of life ( $\geq 125 \mathrm{mg} / \mathrm{kg}$ feed) [19] and in growing ducks of 12-14 weeks old (20 mg/kg feed) [22]. No mortality has been recorded in laying hens, turkeys or older broiler chickens fed high doses of $\mathrm{FB}_{1}(\geq 200 \mathrm{mg} / \mathrm{kg}$ feed) for several weeks $[20,21,23,25]$. Moreover, it has been shown that FBs can reduce growth performance, and induce alterations in serum constituents and enzyme activities demonstrating hepatic toxicity in broilers, turkeys and ducks [20-22,24-28].

In different animal species it is shown that FBs are absorbed very poorly after oral administration. Vudathula et al. [29] showed an oral bioavailability (F) of $0.71 \%$ in laying hens administered $2 \mathrm{mg}$ $[14 \mathrm{C}] \mathrm{FB}_{1} / \mathrm{kg}$ bodyweight $(\mathrm{BW})$. In turkeys and ducks, a similar $\mathrm{F}$ was demonstrated after administering $100 \mathrm{mg} \mathrm{FB} / \mathrm{kg} \mathrm{BW}$, namely $2.0 \%-2.3 \%$ and $3.2 \%$, respectively [27,28]. Benlashehr et al. [30] demonstrated that the toxicokinetics parameters of $\mathrm{FB}_{2}$ are not strongly different from these of $\mathrm{FB}_{1}$ in ducks and turkeys. Furthermore, the intestinal absorption of FBs in avian species is comparable with mammalian species [31-33]. This poor intestinal absorption of FBs has been appointed as the "fumonisin paradox" by Shier [34], or how a toxin can induce liver failure in poultry although it is not effectively absorbed after oral intake. Because the mycotoxins DON and FBs frequently co-occur, and taken into account that FBs have a low oral bioavailability in healthy animals and DON impairs the intestinal barrier and/or decreases the total intestinal absorption surface area, the aim of this study was to investigate whether chronic exposure to DON could influence the intestinal absorption of FBs leading to an altered exposure and increased toxic effects of this mycotoxin in broiler chickens. Because $\mathrm{FB}_{1}$ is the most abundant of the $\mathrm{FBs}$ in feed, and toxicokinetics parameters of $\mathrm{FB}_{1}$ en $\mathrm{FB}_{2}$ are strongly similar [30], the impact of DON on the toxicokinetics parameters of $\mathrm{FB}_{1}$ was investigated.

\section{Results and Discussion}

No significant effects on BW or feed intake were seen after chronic exposure to DON (data not shown). For each diet, control and DON contaminated, no macroscopic lesions were found during gross postmortem examination.

After a single oral bolus administration of $2.5 \mathrm{mg} \mathrm{FBs} / \mathrm{kg} \mathrm{BW}(1.91 \mathrm{mg} \mathrm{FB} 1$ and $0.59 \mathrm{mg} \mathrm{FB}$ ), quantifiable plasma concentrations of $\mathrm{FB}_{1}$ were detected (Figure 1). The dose was calculated based on the European maximum guidance level of $20 \mathrm{mg} \mathrm{FB} 1+\mathrm{FB}_{2} / \mathrm{kg}$ feed [35] and the daily feed intake of the birds $(125 \mathrm{~g} / \mathrm{kg} \mathrm{BW})$. As shown in Figure 1, the plasma concentration-time profile revealed that $\mathrm{FB}_{1}$ reached the maximum plasma concentration $\left(\mathrm{T}_{\max }\right)$ at $20 \mathrm{~min}$ after oral dosing in both control and DON contaminated group. This rapid appearance of $\mathrm{FB}_{1}$ in the systemic circulation indicates that the ingested toxin is absorbed mainly in the proximal part of the intestinal tract. The $T_{\max }$ was reached more rapidly compared to studies in layers, turkeys and ducks, where a $T_{\max }$ of $60 \mathrm{~min}, 180 \mathrm{~min}$ and 60-120 min has been described, respectively [27-29]. This difference might be induced by feed deprivation prior to oral $\mathrm{FB}_{1}$ administration in the present study, whereas in the other studies feed was not deprived. The delaying effect of feed on absorption of mycotoxins has previously been described for DON in pigs with a $\mathrm{T}_{\max }$ of $1.3 \mathrm{~h}$ and $4.1 \mathrm{~h}$ in fasted and fed pigs, respectively [36,37]. 


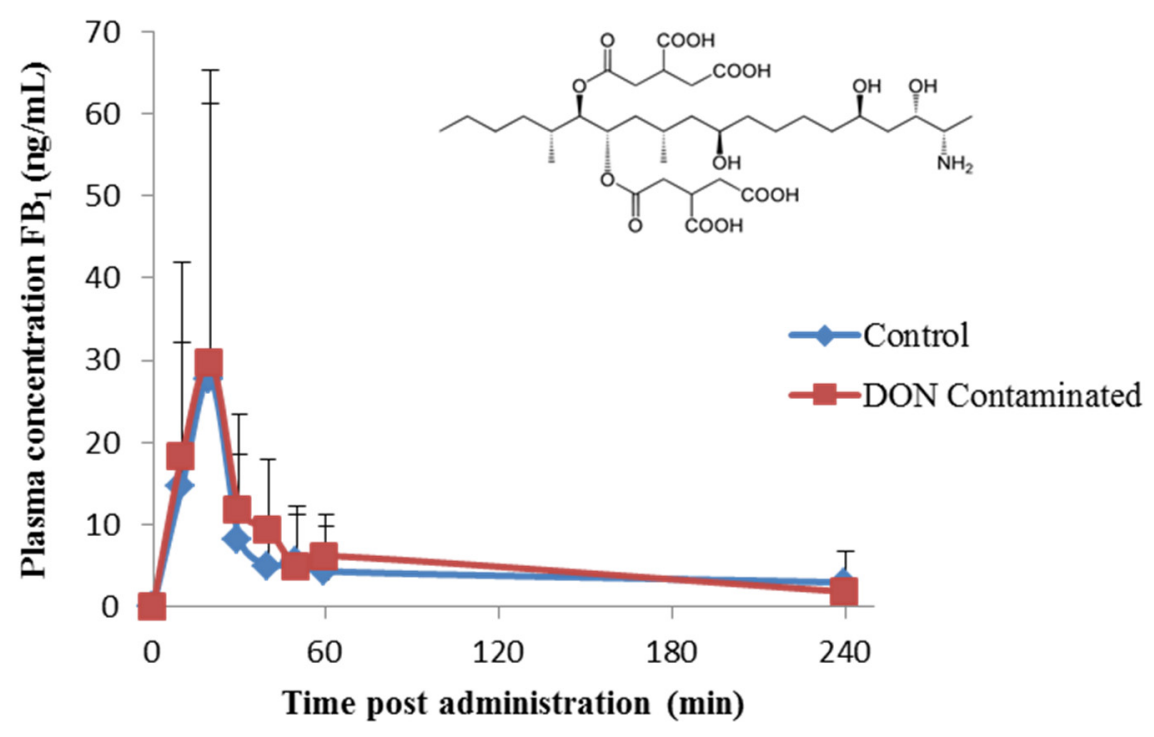

Figure 1. Chemical structure (insert) and plasma concentration-time profile of fumonisin $\mathrm{B}_{1}\left(\mathrm{FB}_{1}\right)$ administered as a single oral bolus of fumonisins to broiler chickens (2.5 mg FBs $/ \mathrm{kg} \mathrm{BW}, n=6$ ), after 3 weeks exposure to either a diet contaminated with deoxynivalenol (DON contaminated, contamination level: $3.12 \mathrm{mg}$ DON/kg feed) or uncontaminated (control) feed. Values are presented as mean + SD.

Oral absorption of $\mathrm{FB}_{1}$ by passive non-ionic transcellular diffusion is very limited as $\mathrm{FB}_{1}$ is mainly negatively charged at the $\mathrm{pH}$ of the duodenum and jejunum in broiler chickens $(\mathrm{pH}=6-7$ [38]; $\mathrm{pKa}$ of the two tricarballylic acid functional groups of $\mathrm{FB}_{1}: 3.49-5.83$ and of the amine functional group: 9.53 [39]). Besides, also limited transcellular transporter mediated $\mathrm{FB}_{1}$ absorption has been suggested [34]. Also, paracellular transport of $\mathrm{FB}_{1}$ is unlikely as the tight junction complex only regulates transport of very small endogenous compounds, not of xenobiotics like mycotoxins and drugs. In this study, it was hypothesized that damage evoked by chronic DON exposure could lead to less complex tight junctions or a "leaky" epithelium thereby enhancing $\mathrm{FB}_{1}$ transport. Indeed, DON negatively affects intestinal integrity and morphology as described previously by our group [9], where the same batches of DON contaminated diets as in the present study were used. This chronic DON exposure causes shortened intestinal villi, leading to a decreased intestinal surface area and possibly leading to a reduced transport [9,10]. This reduced surface area could thus abolish the possible increased paracellular transport. However, the maximum plasma concentration $\left(\mathrm{C}_{\max }\right)$ was similar in chickens fed the control feed and the DON contaminated feed, respectively $0.033 \pm 0.0213 \mu \mathrm{g} / \mathrm{mL}$ and $0.035 \pm 0.0248 \mu \mathrm{g} / \mathrm{mL}$. In accordance, Vudathala et al. [29] showed a $\mathrm{C}_{\max }$ of $0.028 \pm 0.103 \mu \mathrm{g} / \mathrm{mL}$ after oral administration of $2 \mathrm{mg}[14 \mathrm{C}] \mathrm{FB}_{1} / \mathrm{kg} \mathrm{BW}$ to laying hens. Furthermore, feeding a DON contaminated diet had no effect on the area under the plasma concentration-time profile of $\mathrm{FB}_{1}$ from time 0 to $2 \mathrm{~h}$ ( $\mathrm{AUC}_{0-2} \mathrm{~h}$ ) when compared to the control group (Table 1), demonstrating that no effect of DON on body exposure to $\mathrm{FB}_{1}$ was observed. Since $\mathrm{FB}_{1}$ was not administered intravenously to the broiler chickens in the present study, the actual absolute oral $\mathrm{F}$ remains unknown. Therefore, the actual volume of distribution (Vd) and total body clearance $(\mathrm{Cl})$ are computed by the modeling software as $\mathrm{Vd} / \mathrm{F}$ and $\mathrm{Cl} / \mathrm{F}$, respectively. The volume of distribution of $\mathrm{FB}_{1}(\mathrm{Vd} / \mathrm{F})$ was similar in both experimental groups, i.e., $206.7 \pm 92.37$ and $234.3 \pm 25.03 \mathrm{~L} / \mathrm{kg}$ in the DON contaminated $v s$. control group, respectively (Table 1). 
Table 1. Main toxicokinetic parameters of fumonisin $\mathrm{B}_{1}\left(\mathrm{FB}_{1}\right)$ administered as a single oral bolus of fumonisins to broiler chickens ( $2.5 \mathrm{mg} \mathrm{FBs} / \mathrm{kg} \mathrm{BW}, n=6)$, after 3 weeks exposure to either a diet contaminated with deoxynivalenol (DON contaminated, contamination level: $3.12 \mathrm{mg} \mathrm{DON} / \mathrm{kg}$ feed) or uncontaminated (control) feed. Values are presented as mean $\pm \mathrm{SD}$.

\begin{tabular}{|c|c|c|}
\hline Toxicokinetic Parameter of $\mathrm{FB}_{1}$ & DON Contaminated & Control \\
\hline$C_{\max }(\mu \mathrm{g} / \mathrm{mL})$ & $0.035 \pm 0.0248$ & $0.033 \pm 0.0213$ \\
\hline $\mathbf{T}_{\max }(\mathbf{m i n})$ & $20 \pm 5.0$ & $20 \pm 5.0$ \\
\hline $\operatorname{AUC}_{0-\mathrm{t}}(\mu \mathrm{g} / \mathrm{mL} \cdot \min )$ & $83.5 \pm 40.21$ & $90.6 \pm 54.07$ \\
\hline$k_{\text {el }}\left(\min ^{-1}\right)$ & $0.0075 \pm 0.00155$ & $0.0078 \pm 0.00052$ \\
\hline $\mathbf{T}_{1 / 2 \mathrm{el}}(\mathrm{min})$ & $98.4 \pm 22.74$ & $106.2 \pm 8.34$ \\
\hline MRT (min) & $150.8 \pm 35.52$ & $165.5 \pm 48.81$ \\
\hline $\mathbf{V d} / \mathbf{F}(\mathbf{L} / \mathbf{k g})$ & $206.7 \pm 92.37$ & $234.3 \pm 25.03$ \\
\hline $\mathrm{Cl} / \mathrm{F}(\mathrm{mL} / \mathrm{min} \cdot \mathrm{kg})$ & $1544.3 \pm 807.33$ & $944.5 \pm 387.33$ \\
\hline Rel F (\%) & 92.2 & 100 \\
\hline
\end{tabular}

$\mathrm{C}_{\max }=$ maximal plasma concentration; $\mathrm{T}_{\max }=$ time to maximal plasma concentration; $\mathrm{AUC}_{0-\mathrm{t}}=$ area under the plasma concentration-time curve from time 0 to $2 \mathrm{~h} ; \mathrm{k}_{\mathrm{el}}=$ elimination rate constant; $\mathrm{T}_{1 / 2 \mathrm{el}}=$ elimination half-life; $\mathrm{MRT}=$ mean residence time; $\mathrm{Vd} / \mathrm{F}=$ volume of distribution divided by the absolute oral bioavailability; $\mathrm{Cl} / \mathrm{F}=$ clearance divided by the absolute oral bioavailability; Rel $\mathrm{F}=$ relative oral bioavailability.

In order to compare the $\mathrm{Vd}$ and $\mathrm{Cl}$ between poultry species, the values obtained for ducks and turkeys by Tardieu et al. [27,28] have been divided by their reported absolute $\mathrm{F}$ as well. The $\mathrm{Vd} / \mathrm{F}$ of broiler chickens was higher compared to ducks and turkeys, namely $74.1-85.8$ and $72.3 \mathrm{~L} / \mathrm{kg}$, respectively. The clearance $(\mathrm{Cl} / \mathrm{F})$ of $\mathrm{FB}_{1}$ obtained after oral administration in broiler chickens was similar in both experimental groups (Table 1), and was comparable to ducks (739-835 mL/min/kg) but was higher compared to turkeys $(234 \mathrm{~mL} / \mathrm{min} / \mathrm{kg})$ [27,28]. Consequently, the elimination half-life $\left(\mathrm{T}_{1 / 2 \mathrm{el}}\right)$ was twice as long in turkeys (214 $\mathrm{min})$ [28] compared to broilers (106 $\mathrm{min})$ and ducks (70 $\mathrm{min})$ [27]. The mean residence time (MRT) was $150.8 \pm 35.52 \mathrm{~min}$ and $165.5 \pm 48.81 \mathrm{~min}$ in the DON contaminated group and the control group, respectively. These results are comparable with ducks (188-200 $\mathrm{min}$ ) [27], but shorter compared to turkeys (408 min) [28]. This study also showed, in accordance to reports in other poultry species [27-29], low plasma levels of FB1 (low ng/mL range) despite the high administered dose $(2.5 \mathrm{mg} \mathrm{FBs} / \mathrm{kg} \mathrm{BW})$. This low oral bioavailability suggests that the systemic exposure to this mycotoxin can therefore be enhanced when the intestinal barrier and integrity is compromised $[17,18]$.

As mentioned before, no significant differences between both groups (control or DON contaminated) could be observed for any of the toxicokinetic parameters (Table 1). Also, DON and its major metabolite, de-epoxydeoxynivalenol (DOM-1), were not detected in plasma in the present study. This is in accordance to Osselaere et al. (2012) [17,18] where, after three-week exposure of broiler chickens to $7.5 \mathrm{mg}$ DON$/ \mathrm{kg}$ feed, no plasma levels of DON or DOM-1 were detected above the limit of quantification $(\mathrm{LOQ}=1 \mathrm{ng} / \mathrm{mL})$. It has been shown that DON also selectively modulates the activities of different intestinal transporter proteins for nutrients, and negatively influences the sodium associated amino acid co-transport for serine and proline [40-42].

Although in literature it has been demonstrated that DON negatively affects the intestinal barrier function, morphology and transporter mediated nutrient transport in different animal species, chronic 
exposure to concentrations respecting the European maximum guidance levels in feed did not affect the oral bioavailability of $\mathrm{FB}_{1}$ administered as a single bolus in broiler chickens.

\section{Experimental Section}

\subsection{Chemicals, Products and Reagents}

DON (25.9 mg DON/g culture material) and FBs (14.07 mg FB $/ \mathrm{g}$ and $4.3 \mathrm{mg} \mathrm{FB} / \mathrm{g}$ culture material) were produced in vitro from cultures of $F$. graminearum (DSMO 4258) and $F$. verticillioides (M-3125) [43,44], respectively, and subsequently purified and crystallized [44,45] (Romer Labs, Tulln, Austria). The standards of $\mathrm{DON}$ and $\mathrm{FB}_{1}$ for the analytical experiments were purchased from Fermentek (Jerusalem, Israel), and Sigma-Aldrich (Bornem, Belgium) for DOM-1. Internal standards (IS) for DON, ${ }^{13} \mathrm{C}_{15}$-DON, and for $\mathrm{FB}_{1},{ }^{13} \mathrm{C}_{34}-\mathrm{FB}_{1}$, were purchased from Romer Labs (Tulln, Austria). The standards were stored at $\leq-15^{\circ} \mathrm{C}$. Water, methanol and acetonitrile (ACN) were of LC-MS grade and were obtained from Biosolve (Valkenswaard, The Netherlands). Glacial acetic acid and formic acid were of analytical grade and obtained from VWR (Leuven, Belgium). Millex ${ }^{\circledR}-$ GV-PVDF filter units $(0.22 \mu \mathrm{m})$ were obtained from Merck-Millipore (Diegem, Belgium).

\subsection{Feed Preparation and Experimental Diets}

Chickens were fed a starter diet during the first eight days of the experiment, and subsequently a grower diet until the end of the trial (day 21). These feeds are further referred to as control diets. The feed composition was described previously in detail $[9,46]$. Briefly, the diet was wheat and rye based, with soybean meal as main protein source during the first 16 days. From day 17 onwards, the same grower diet was fed with the exception that fishmeal replaced soybean meal as main protein source. Screening of the control feeds for contamination with mycotoxins was performed by a LC-MS/MS method, as described by Monbaliu et al. [47]. To produce a starter and grower diet experimentally contaminated with DON, purified crystallized DON was added to $500 \mathrm{~g}$ of control feed. This premix was then mixed with $5 \mathrm{~kg}$ of control feed to assure homogeneous distribution of the toxin. The premix was finally mixed for $20 \mathrm{~min}$ in the total amount of feed needed for each diet. To test the homogeneity of DON in the diets, a sample was taken at three different locations in the batch and analyzed for DON as described for the control diets.

Different tested mycotoxins, their limit of detection (LOD) and limit of quantification (LOQ) were as previously described by Antonissen et al. [9]. Trace amounts of $\mathrm{FB}_{1}$ were detected in the control feed and the contaminated feed, but the mean level of $64 \mu \mathrm{g} / \mathrm{kg}$ feed was below the LOQ (116 $\mu \mathrm{g} / \mathrm{kg})$. The levels of DON and all other tested mycotoxins in the different batches of control feed were below the LOQ. The average level of DON in the different batches of contaminated feed was $3.12 \pm 0.234 \mathrm{mg}$ DON $/ \mathrm{kg}$ feed, which is below the EU maximum guidance level of $5 \mathrm{mg}$ DON/kg feed for poultry [35]. The contaminated feed contained also $0.020 \pm 0.007 \mathrm{mg} 3$-acetyl DON $/ \mathrm{kg}$ feed and $0.038 \pm 0.031 \mathrm{mg} 15$-acetyl DON/kg feed. 


\subsection{Animal Experiment}

Twelve one-day old broiler chickens of mixed gender (Ross 308) were randomly allocated to two different groups of six birds $\left(3 \delta^{\wedge} / 3 q\right)$. An $18 \mathrm{~h} / 6 \mathrm{~h}$ light/darkness program was applied. The environmental temperature was adjusted to the changing needs of the animals according to their age. The birds of one group were fed uncontaminated feed ad libitum (control group) whereas the birds of the other group were fed the DON contaminated feed (DON contaminated group). Drinking water was provided ad libitum during the entire experiment. Feed intake was measured daily per group. The BW of all animals was measured on day 1, 8, 15 and day 21. After three weeks, chickens were fasted overnight $(8 \mathrm{~h})$, and subsequently all birds were administered $2.5 \mathrm{mg} \mathrm{FB} 1+\mathrm{FB}_{2} / \mathrm{kg} \mathrm{BW}$ as an intra-crop bolus. The $2.5 \mathrm{mg} \mathrm{FBs} / \mathrm{kg} \mathrm{BW}$ corresponded with $1.91 \mathrm{mg} \mathrm{FB} / \mathrm{kg} \mathrm{BW}$ and $0.59 \mathrm{mg} \mathrm{FB} / \mathrm{kg} \mathrm{BW}$. Blood was sampled by direct venipuncture from the leg vein (vena metatarsalis plantaris superficialis) into heparinized tubes before ( $0 \mathrm{~min})$ and at different time points after administration, i.e., 10, 20, 30, 40, 50, 60 and $240 \mathrm{~min}$. No feed was provided during the toxicokinetic experiment. Blood samples were centrifuged $\left(2851 \times \mathrm{g}, 10 \mathrm{~min}, 4{ }^{\circ} \mathrm{C}\right)$ and plasma was stored at $\leq-15{ }^{\circ} \mathrm{C}$ until analysis. At the end of the experiment, all the animals were euthanized and a macroscopic post-mortem examination was carried out to reveal a possible pathology.

The animal experiment was approved by the Ethical Committee of the Faculty of Veterinary Medicine and Bioscience Engineering of Ghent University (EC 2012/075).

\subsection{Quantification of DON, DOM-1 and FB 1 in Plasma}

Two LC-MS/MS methods were used to quantify DON and DOM-1, and FB 1 in the plasma samples, based on Devreese et al. [48]. The sample preparation procedure was the same for both methods. In brief, to $250 \mu \mathrm{L}$ of plasma $12.5 \mu \mathrm{L}$ of both IS and $750 \mu \mathrm{L}$ of ACN were added, followed by a vortex mixing (15 s) and centrifugation step $\left(8517 \times \mathrm{g}, 10 \mathrm{~min}, 4^{\circ} \mathrm{C}\right)$. Next, the supernatant was transferred to another tube and evaporated using a gentle nitrogen $\left(\mathrm{N}_{2}\right)$ stream $\left(45 \pm 5^{\circ} \mathrm{C}\right)$. The dry residue was reconstituted in $200 \mu \mathrm{L}$ of water/methanol $(85 / 15, v / v)$. After vortex mixing (15 s), the sample was passed through a Millex ${ }^{\circledR}$ GV-PVDF filter $(0.22 \mu \mathrm{m})$ and transferred into an autosampler vial. An aliquot $(5 \mu \mathrm{L})$ was injected onto the LC-MS/MS instrument. The LC system consisted of a quaternary, low-pressure mixing pump with vacuum degassing, type Surveyor MSpump Plus and an autosampler with temperature controlled tray and column oven, type Autosampler Plus, from ThermoFisher Scientific (Breda, The Netherlands). Chromatographic separation was achieved on a Hypersil Gold column $(50 \mathrm{~mm} \times 2.1 \mathrm{~mm}$ i.d., dp: $1.9 \mu \mathrm{m})$ in combination with a guard column of the same type $(10 \mathrm{~mm} \times 2.1 \mathrm{~mm}$ i.d., dp: $3 \mu \mathrm{m})$, both from ThermoFisher Scientific. A gradient elution program was performed with $0.1 \%$ glacial acetic acid (DON, DOM-1) or $0.1 \%$ acetic acid $\left(\mathrm{FB}_{1}\right)$ in water and methanol as mobile phases. The LC column effluent was interfaced to a TSQ ${ }^{\circledR}$ Quantum Ultra triple quadrupole mass spectrometer, equipped with a heated electrospray ionization (h-ESI) probe operating in the negative ionization mode for DON and DOM-1, and in the positive mode for $\mathrm{FB}_{1}$ (all from ThermoFisher Scientific). Following selected reaction monitoring (SRM) transitions were monitored and used for quantification: for DON $m / z 355.2>265.1$ and $355.2>295.1$, for DOM-1 m/z 339.1 > 59.1 and 339.1 > 249.0, for ${ }^{13} \mathrm{C}_{15}$-DON $\mathrm{m} / z 370.2>279.1$ and $370.2>310.1$, 
for $\mathrm{FB}_{1} \mathrm{~m} / \mathrm{z} 722.3>333.9$ and $722.3>352.4$ and for ${ }^{13} \mathrm{C}_{34}-\mathrm{FB}_{1} 756.4>356.2$ and $756.4>374.2$. The LOQs of DON, DOM-1 and FB1 were 1, 2 and $1 \mathrm{ng} / \mathrm{mL}$, respectively, whereas the LODs were 0.05 , 0.04 and $0.08 \mathrm{ng} / \mathrm{mL}$, respectively.

\subsection{Toxicokinetic and Statistical Analysis}

Toxicokinetic analysis was performed with WinNonlin 6.3 following a non-compartmental model (Pharsight, St. Louis, MO, USA). The most important toxicokinetic parameters of $\mathrm{FB}_{1}$ were calculated: maximal plasma concentration $\left(\mathrm{C}_{\max }\right)$, time to maximal plasma concentration $\left(\mathrm{T}_{\max }\right)$, area under the plasma concentration-time curve from time 0 to $2 \mathrm{~h}\left(\mathrm{AUC}_{0-\mathrm{t}}\right)$, elimination rate constant $\left(\mathrm{k}_{\mathrm{el}}\right)$, elimination half-life $\left(\mathrm{T}_{1 / 2 \mathrm{el}}\right)$, mean residence time (MRT), volume of distribution divided by the absolute oral bioavailability $(\mathrm{Vd} / \mathrm{F})$, and clearance divided by the absolute oral bioavailability $(\mathrm{Cl} / \mathrm{F})$. The relative oral bioavailability (Rel F) was calculated according to the following formula:

$$
\text { Rel F }=\text { AUC }_{0-\mathrm{t}} \text { DON contaminated/AUC } 0 \text {-t control }
$$

Statistical analysis was done using a Student's $t$-test (SPSS 20.0, IBM, Chicago, IL, USA). The significance level was set at 0.05 .

\section{Conclusions}

Previous literature reports have shown that DON impairs the intestinal morphology, integrity and transporter mediated nutrient transport, both in vitro and in vivo. Therefore, it was hypothesized that chronic exposure to DON could influence the oral bioavailability of FBs in broiler chickens, leading to altered exposure and toxic effects of this mycotoxin. In the present study, no significant effects on the main toxicokinetic parameters and oral bioavailability of $\mathrm{FB}_{1}$ after a single oral bolus administration in broiler chickens were found after chronic exposure to DON.

\section{Acknowledgments}

Gunther Antonissen was supported by a PhD fellowship from Biomin GmbH (Herzogenburg, Austria). Mathias Devreese would like to thank the "Agency for Innovation by Science and Technology" (IWT, Brussels, Belgium) for its financial support (SB grant 2010 No 101301). Mia Eeckhout, Marina Van Hecke and Yvan De Bock from the department of Applied Biosciences, Faculty of Bioscience Engineering, Ghent University are acknowledged for the preparation of the experimental diets. Sarah De Saeger and Christ'l Detavernier from the department of Bio-analysis, Faculty of Pharmaceutical Sciences, Ghent University, are acknowledged for the mycotoxin analyses of the feed samples.

\section{Author Contributions}

Study design: Gunther Antonissen, Mathias Devreese, Filip Van Immerseel, An Martel and Siska Croubels; Animal Experiment: Gunther Antonissen and Mathias Devreese; Plasma analysis: Mathias Devreese and Siegrid De Baere; Toxicokinetic and statistical analysis: Gunther Antonissen and Mathias Devreese; Provided mycotoxins for animal experiment: Sabine Hessenberger; Preparation of the manuscript: Gunther Antonissen, Mathias Devreese and Siska Croubels. 


\section{Conflicts of Interest}

The authors declare no conflict of interest.

\section{References}

1. Binder, E.M. Managing the risk of mycotoxins in modern feed production. Anim. Feed Sci. Technol. 2007, 133, 149-166.

2. Edwards, S.G. Zearalenone risk in european wheat. World Mycotoxin J. 2011, 4, 433-438.

3. Streit, E.; Naehrer, K.; Rodrigues, I.; Schatzmayr, G. Mycotoxin occurrence in feed and feed raw materials worldwide: Long-term analysis with special focus on Europe and Asia. J. Sci. Food Agric. 2013, 93, 2892-2899.

4. Streit, E.; Schatzmayr, G.; Tassis, P.; Tzika, E.; Marin, D.; Taranu, I.; Tabuc, C.; Nicolau, A.; Aprodu, I.; Puel, O. Current situation of mycotoxin contamination and co-occurrence in animal feed-focus on Europe. Toxins 2012, 4, 788-809.

5. Bouhet, S.; Oswald, I.P. The effects of mycotoxins, fungal food contaminants, on the intestinal epithelial cell-derived innate immune response. Vet. Immunol. Immunopathol. 2005, 108, 199-209.

6. Bracarense, A.P.F.; Lucioli, J.; Grenier, B.; Drociunas Pacheco, G.; Moll, W.D.; Schatzmayr, G.; Oswald, I.P. Chronic ingestion of deoxynivalenol and fumonisin, alone or in interaction, induces morphological and immunological changes in the intestine of piglets. Br. J. Nutr. 2012, 107, 1776-1786.

7. Rotter, B.A. Invited review: Toxicology of deoxynivalenol (vomitoxin). J. Toxicol. Environ. Health A 1996, 48, 1-34.

8. Osselaere, A.; Santos, R.; Hautekiet, V.; de Backer, P.; Chiers, K.; Ducatelle, R.; Croubels, S. Deoxynivalenol impairs hepatic and intestinal gene expression of selected oxidative stress, tight junction and inflammation proteins in broiler chickens, but addition of an adsorbing agent shifts the effects to the distal parts of the small intestine. PLoS One 2013, 8, e69014.

9. Antonissen, G.; van Immerseel, F.; Pasmans, F.; Ducatelle, R.; Haesebrouck, F.; Timbermont, L.; Verlinden, M.; Janssens, G.P.; Eeckhaut, V.; Eeckhout, M.; et al. The mycotoxin deoxynivalenol predisposes for the development of Clostridium perfringens-induced necrotic enteritis in broiler chickens. PLoS One 2014, 9, e108775.

10. Yunus, A.W.; Blajet-Kosicka, A.; Kosicki, R.; Khan, M.Z.; Rehman, H.; Bohm, J. Deoxynivalenol as a contaminant of broiler feed: Intestinal development, absorptive functionality, and metabolism of the mycotoxin. Poult. Sci. 2012, 91, 852-861.

11. Devreese, M.; Girgis, G.N.; Tran, S.T.; de Baere, S.; de Backer, P.; Croubels, S.; Smith, T.K. The effects of feed-borne Fusarium mycotoxins and glucomannan in turkey poults based on specific and non-specific parameters. Food Chem. Toxicol. 2014, 63, 69-75.

12. Pinton, P.; Nougayrède, J.P.; del Rio, J.C.; Moreno, C.; Marin, D.E.; Ferrier, L.; Bracarense, A.P.; Kolf-Clauw, M.; Oswald, I.P. The food contaminant deoxynivalenol, decreases intestinal barrier permeability and reduces claudin expression. Toxicol. Appl. Pharm. 2009, 237, 41-48. 
13. Goossens, J.; Pasmans, F.; Verbrugghe, E.; Vandenbroucke, V.; de Baere, S.; Meyer, E.; Haesebrouck, F.; de Backer, P.; Croubels, S. Porcine intestinal epithelial barrier disruption by the fusarium mycotoxins deoxynivalenol and T-2 toxin promotes transepithelial passage of doxycycline and paromomycin. BMC Vet. Res. 2012, 8, 245.

14. Voss, K.A.; Smith, G.W.; Haschek, W.M. Fumonisins: Toxicokinetics, mechanism of action and toxicity. Anim. Feed Sci. Technol. 2007, 137, 299-325.

15. Devreese, M.; de Backer, P.; Croubels, S. Overview of the most important mycotoxins for the pig and poultry husbandry. Vlaams Diergen. Tijds. 2013, 82, 171-180.

16. Riley, R.T.; Enongene, E.; Voss, K.A.; Norred, W.P.; Meredith, F.I.; Sharma, R.P.; Spitsbergen, J.; Williams, D.E.; Carlson, D.B.; Merrill, A.H. Sphingolipid perturbations as mechanisms for fumonisin carcinogenesis. Environ. Health Persp. 2001, 109, 301-308.

17. Bouhet, S.; Oswald, I.P. The intestine as a possible target for fumonisin toxicity. Mol. Nutr. Food Res. 2007, 51, 925-931.

18. Grenier, B.; Applegate, T.J. Modulation of intestinal functions following mycotoxin ingestion: Meta-analysis of published experiments in animals. Toxins 2013, 5, 396-430.

19. Javed, T.; Bennett, G.A.; Richard, J.L.; Dombrinkkurtzman, M.A.; Cote, L.M.; Buck, W.B. Mortality in broiler chicks on feed amended with Fusarium proliferatum culture material or with purified fumonisin $\mathrm{B}_{1}$ and moniliformin. Mycopathologia 1993, 123, 171-184.

20. Ledoux, D.R.; Brown, T.P.; Weibking, T.S.; Rottinghaus, G.E. Fumonisin toxicity in broiler chicks. J. Vet. Diagn. Investig. 1992, 4, 330-333.

21. Weibking, T.S.; Ledoux, D.R.; Bermudez, A.J.; Turk, J.R.; Rottinghaus, G.E.; Wang, E.; Merrill, A.H. Effects of feeding Fusarium moniliforme culture material, containing known levels of fumonisin $\mathrm{B}_{1}$, on the young broiler chick. Poult. Sci. 1993, 72, 456-466.

22. Tardieu, D.; Bailly, J.D.; Benard, G.; Tran, T.S.; Guerre, P. Toxicity of maize containing known levels of fumonisin B 1 during force-feeding of ducks. Poult. Sci. 2004, 83, 1287-1293.

23. Kubena, L.F.; Harvey, R.B.; Buckley, S.A.; Bailey, R.H.; Rottinghaus, G.E. Effects of long-term feeding of diets containing moniliformin, supplied by Fusarium fujikuroi culture material, and fumonisin, supplied by Fusarium moniliforme culture material, to laying hens. Poult. Sci. 1999, $78,1499-1505$.

24. Tran, S.T.; Auvergne, A.; Benard, G.; Bailly, J.D.; Tardieu, D.; Babile, R.; Guerre, P. Chronic effects of fumonisin $\mathrm{B}_{1}$ on ducks. Poult. Sci. 2005, 84, 22-28.

25. Ledoux, D.R.; Bermudez, A.J.; Rottinghaus, G.E. Effects of feeding Fusarium moniliforme culture material, containing known levels of fumonisin $\mathrm{B}_{1}$, in the young turkey poult. Poult. Sci. 1996, 75, 1472-1478.

26. Broomhead, J.N.; Ledoux, D.R.; Bermudez, A.J.; Rottinghaus, G.E. Chronic effects of fumonisin $\mathrm{B}_{1}$ in broilers and turkeys fed dietary treatments to market age. Poult. Sci. 2002, 81, 56-61.

27. Tardieu, D.; Bailly, J.D.; Benlashehr, I.; Auby, A.; Jouglar, J.Y.; Guerre, P. Tissue persistence of fumonisin $\mathrm{B}_{1}$ in ducks and after exposure to a diet containing the maximum European tolerance for fumonisins in avian feeds. Chem. Biol. Interact. 2009, 182, 239-244.

28. Tardieu, D.; Bailly, J.D.; Skiba, F.; Grosjean, F.; Guerre, P. Toxicokinetics of fumonisin B 1 in turkey poults and tissue persistence after exposure to a diet containing the maximum European tolerance for fumonisins in avian feeds. Food Chem. Toxicol. 2008, 46, 3213-3218. 
29. Vudathala, D.K.; Prelusky, D.B.; Ayroud, M.; Trenholm, H.L.; Miller, J.D. Pharmacokinetic fate and pathological effects of ${ }^{14} \mathrm{C}$-fumonisin $\mathrm{B}_{1}$ in laying hens. Nat. Toxins 1994, 2, 81-88.

30. Benlashehr, I.; Repussard, C.; Jouglar, J.Y.; Tardieu, D.; Guerre, P. Toxicokinetics of fumonisin $\mathrm{B}_{2}$ in ducks and turkeys. Poult. Sci. 2011, 90, 1671-1675.

31. Prelusky, D.B.; Trenholm, H.L.; Savard, M.E. Pharmacokinetic fate of 14C-labelled fumonisin B1 in swine. Nat. Toxins 1994, 2, 73-80.

32. Martinez-Larranaga, M.R.; Anadon, A.; Diaz, M.J.; Fernandez-Cruz, M.L.; Martinez, M.A.; Frejo, M.T.; Martinez, M.; Fernandez, R.; Anton, R.M.; Morales, M.E.; et al. Toxicokinetics and oral bioavailability of fumonisin $\mathrm{B}_{1}$. Vet. Hum. Toxicol. 1999, 41, 357-362.

33. Shephard, G.S.; Thiel, P.G.; Sydenham, E.W.; Savard, M.E. Fate of a single dose of ${ }^{14}$ C-labelled fumonisin $\mathrm{B}_{1}$ in vervet monkeys. Nat. Toxins 1995, 3, 145-150.

34. Shier, W.T. The fumonisin paradox: A review of research on oral bioavailability of fumonisin $\mathrm{B}_{1}$, a mycotoxin produced by fusarium moniliforme. J. Toxicol. Toxin Rev. 2000, 19, 161-187.

35. European Commission. Commission recommendation of 17 August 2006 on the presence of deoxynivalenol, zearalenone, ochratoxin A, T-2 and HT-2 and fumonisins in products intended for animal feeding. Off. J. Eur. Union 2006, 229, 7-9.

36. Dänicke, S.; Valenta, H.; Doll, S. On the toxicokinetics and the metabolism of deoxynivalenol (DON) in the pig. Arch. Anim. Nutr. 2004, 58, 169-180.

37. Devreese, M.; Antonissen, G.; de Backer, P.; Croubels, S. Efficacy of active carbon towards the absorption of deoxynivalenol in pigs. Toxins 2014, 6, 2998-3004.

38. Maresca, M. From the gut to the brain: Journey and pathophysiological effects of the food-associated trichothecene mycotoxin deoxynivalenol. Toxins 2013, 5, 784-820.

39. Mangia, M. Free and Hidden Fumonisins in Maize and Gluten-Free Products. Ph.D. Thesis, University of Parma, Parma, Italy, 2009.

40. Awad, W.A.; Rehman, H.; Bohm, J.; Razzazi-Fazeli, E.; Zentek, J. Effects of luminal deoxynivalenol and L-proline on electrophysiological parameters in the jejunums of laying hens. Poult. Sci. 2005, 84, 928-932.

41. Maresca, M.; Mahfoud, R.; Garmy, N.; Fantini, J. The mycotoxin deoxynivalenol affects nutrient absorption in human intestinal epithelial cells. J. Nutr. 2002, 132, 2723-2731.

42. Dietrich, B.; Neuenschwander, S.; Bucher, B.; Wenk, C. Fusarium mycotoxin-contaminated wheat containing deoxynivalenol alters the gene expression in the liver and the jejunum of broilers. Animal 2011, 6, 278-291.

43. Leslie, J.F.; Plattner, R.D.; Desjardins, A.E.; Klittich, C.J.R. Fumonisin B1 production by strains from different mating populations of Gibberella fujikuroi (Fusarium section Liseola). Phytopathology 1992, 82, 341-345.

44. Altpeter, F.; Posselt, U.K. Production of high quantities of 3-acetyldeoxynivalenol and deoxynivalenol. Appl. Microbiol. Biotechnol. 1994, 41, 384-387.

45. Hahn, I.; Nagl, V.; Schwartz-Zimmermann, H.E.; Varga, E.; Schwarz, C.; Slavik, V.; Reisinger, N.; Malachová, A.; Cirlini, M.; Generotti, S. Effects of orally administered fumonisin B1 $\left(\mathrm{FB}_{1}\right)$, partially hydrolysed $\mathrm{FB}_{1}$, hydrolysed $\mathrm{FB}_{1}$ and $n$-(1-deoxy-d-fructos-1-yl) $\mathrm{FB}_{1}$ on the sphingolipid metabolism in rats. Food Chem. Toxicol. 2015, 76, 11-18. 
46. Gholamiandehkordi, A.R.; Timbermont, L.; Lanckriet, A.; van Den Broeck, W.; Pedersen, K.; Dewulf, J.; Pasmans, F.; Haesebrouck, F.; Ducatelle, R.; van Immerseel, F. Quantification of gut lesions in a subclinical necrotic enteritis model. Avian Pathol. 2007, 36, 375-382.

47. Monbaliu, S.; van Poucke, C.; Detavernier, C.; Dumoulin, F.; van de Velde, M.; Schoeters, E.; van Dyck, S.; Averkieva, O.; van Peteghem, C.; de Saeger, S. Occurrence of mycotoxins in feed as analyzed by a multi-mycotoxin lc-ms/ms method. J. Agric. Food Chem. 2010, 58, 66-71.

48. Devreese, M.; de Baere, S.; de Backer, P.; Croubels, S. Quantitative determination of several toxicological important mycotoxins in pig plasma using multi-mycotoxin and analyte-specific high performance liquid chromatography-tandem mass spectrometric methods. J. Chromatogr. A 2012, 1257, 74-80.

(C) 2015 by the authors; licensee MDPI, Basel, Switzerland. This article is an open access article distributed under the terms and conditions of the Creative Commons Attribution license (http://creativecommons.org/licenses/by/4.0/). 